\title{
Evocación personal
}

\author{
Augusto Alcocer Martínez \\ Departamento Académico de Lingüística
}

\begin{abstract}
S e me ha encomendado hablar aquí del magisterio de Alberto Escobar D) partiendo de mi experiencia personal. Me detendré en un solo aspecto. Hace casi cuatro décadas fui alumno suyo en el primer año de la Sección de Cultura General de nuestra Facultad de Letras. Precisamente el año de 1959, en una Lima de poco más de un millón de habitantes preocupada por la lentitud de su crecimiento poblacional, tuve la fortuna de conocerlo. Eran los tiempos de los albores del tritunfo de la Revolución Cubana y en el Perú, de la contradictoria "Convivencia Política" del Presidente Manuel Prado.
\end{abstract}

Quienes nos disponíamos â dar inicio a la vida en las aulas, alumnos cuyos apellidos estaban comprendidos entre las letras " $\mathrm{A}$ " $\mathrm{y}$ " $\mathrm{C}$ " -por efecto de un tardío desdoblamiento- de grupos $\mathrm{C}$ bamos-a contar con un nuevo profesor de Castellano. "Jorge Puccinelli Converso»

Quiso el azar que tanto Escobar como el que habla confluyéramos desde muy distintos caminos y en el momento preciso, en el viejo caserón que la Facultad utilizaba para el dictado de clases situado en la antigua calle de Padre Gerónimo (actual jirón Puno).

* Discurso pronunciado el 10 de diciembre de 1998, en el Salón de Actos de la Facultad de Letras, en el homenaje que la Facultad le rindió al Dr. Alberto Escobar, y que contó con su asistencia. 
La vida universitaria del referido año fue curiosamente atípica, pues no estallaron las acostumbradas huelgas estudiantiles y los más graves acontecimientos sociopolíticos que se produjeron en la época no llegaron a perturbar el normal desarrollo del año lectivo. Salvo el reemplazo del antiguo profesor (que bastante hizo con invitarnos al estrado para hablar de nuestras propias vidas) por otro, muy joven, que según se rumoreaba, venía de Europa, pertrechado con las más avanzadas armas de la ciencia Lingüística y la Literatura, condición que nos infundía una mezcla de expectativa, entusiasmo y de cierto temor.

En verdad, habíamos tenido la grata impresión de escucharlo el 17 de abril del ya citado año con motivo de la inauguración del año académico de la Facultad. Le correspondió a Escobar el honor de pronunciar el discurso de orden: El lenguaje y la función social de la Universidad que alcanzó una gran repercusión en el Claustro.

La pieza oratoria leída con franqueza y convicción presentó aquella noche una amena visión panorámica de los mâs importantes estudios realizados en torno al lenguaje a lo largo de la historia para llegar a la comprensión de cuanto a esa fecha (finales de los cincuenta) conocía la Lingüística acerca del fenómeno sonoro. Reconocido el objeto y fijados los métodos de aplicación de la Ciencia del Lenguaje, Escobar se dio el ingente trabajo de confrontarlos con lo que en pleno siglo XX se hacía en la enseñanza-aprendizaje del español en el Perú: Orientaciôn gramatical y cerraçamente prescriptiva que

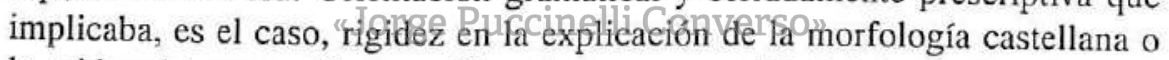
la aridez del percentil ortográfico. La penosa realidad del empobrecimiento del dominio lingüístico a causa de diversidad de factores como la disminución de la importancia formativa de la Literatura, Historia o Filosofía, el abandono del aprendizaje de las llamadas lenguas clásicas, y por ende, el trabajo directo sobre textos latinos, sobre el lenguaje en acción sorprendiendo la actividad de la lengua en la realidad que después abstrae la Gramática. También enumeraba como causas del deterioro en la enseñanza del Castellano los cambios que se operaban en la vida social, en la familia peruana de medio siglo, que de la activa participación en la sobremesa, la charla hogareña, la lectura en coro se iba pasando a las diversiones mudas del cine y la televisión, a ello se sumaba la errada directiva del Ministerio de Educación de aplicar las llamadas pruebas objetivas que bloqueaban en los alumnos la posibilidad de ejercicio mental. Las ya registradas condiciones en que se debatía la enseñanza del Castellano entre nosotros obligaron al orador a preguntarse si ¿era la 
enseñanza de tipo gramatical y cerradamente normativa la vía idónea para "hablar y escribir correctamente un idioma"?

Escobar contestó resueltamente: "que si la noción de lenguaje alcanzado por la Lingüística de la época (realidad polar, móvil, enérgica, creación o interpretación de la herencia cultural) se comparara con la modalidad de Gramática normativa que se enseñaba en el Perú (un código desespiritualizado de normas y excepciones), sería de toda evidencia que con el gramaticismo en boga no podría pensarse en conseguir un aceptable resultado práctico".

Para la enseñanza del Castellano en el nivel superior o universitario, proponía que el estudio vincule la relación Lengua y Cultura a través de temas parciales de Historia Cultural e Historia de la Civilización, esta estrategia permitiría al profesor de la asignatura variar cada año el syllabus e incitaría al alumno hacia la comprensión total del Lenguaje, pues, no de otra forma se manifiesta la teoría del sistema de la lengua. Priorizaba, además, la utilización a fondo del método de la Estilística (apenas conocido en nuestro medio) para alcanzar el mayor logro pédagógico.

Recomendaba el trabajo intensivo con las dicotomías lengua/habla, sincronía/diacronía, significante/significado, aún vigente en los actuales programas universitarios. La incorporación del método Palabras y Cosas, el estudio de las toponimias -intuía Escobar- serían especialmente útiles en un contexto multicultural y plurilingue como el nuestro. "Si básicamente se emplearan los temas ya señalados nó se podrí ya decir-concluye- que el estudio de la lengua es inútil y absurdo, que está de espaldas a la sociedad y no se confundiría con la charlatanería hueca y cursi de los filólogos silvestres...".

La novedad de los planteamientos de Escobar suscitaron un inmediato cambio de opiniones entre los especialistas que permitieron a las autoridades de la Facultad encarar con amplitud de miras, sensatez y pragmatismo, el problema de la enseñanza de una materia humanística y formativa, considerada insustituible en el Plan de Estudios de Letras. Se decidió encargar el ictado al Dr. Alberto Escobar ya que, como acabamos de señalar, muy recientemente había sido él quien, con los mejores argumentos, reclamaba profundas reformas en la conducción del curso básico de Castellano. Situado ya en la cresta de la ola aceptó de buen grado la responsabilidad. 
Desde nuestra perspectiva de anónimo cachimbo, observábamos que Escobar aceptaba más que una responsabilidad, en el fondo asumía un verdadero reto. Pensábamos iqué duda cabe! que nuestro homenajeado profesor, durante seis años adiestrado en el Viejo Mundo, había retornado a la Patria con el sincero deseo de servirla, sentía que era su deber participar activamente en una auténtica renovación de los estudios lingüísticos y literarios. Era ésta una ocasión propicia de aportar. Alcanzar el éxito académico en San Marcos suponía, por reflejo, transferir normas y modelos científicos al resto de las cinco universidades que entonces funcionaban en el Perú.

Comenzó el curso experimental (que como tal se dictó en una sola oportunidad) y apareció el nuevo titular acompañado de sus profesores asistentes: El llorado Luis Ramírez Mendoza (no era aún Luis Hernán) y Julio Díaz Falconí quienes necesitaron poco tiempo para demostrar su valer. Era alto, de bigotes, creo que la veladura de las gafas me impedía reparar en los ojos, aunque a mediados de los sesenta una renombrada bibliotecaria que seguía estudios de Literatura me confesé en tono insinuante que eran verdes, pausado en el andar, iba a clase pulcramente vestido. Muy compuesto en el trato con los alumnos, se dirigía a nosotros tratándonos de usted. Hablaba con voz normal y agradable, facifitando la atención. Su afable seriedad sólo dejaba paso a una amplia sonrisa cuando alguno de nuestros disparates reunía méritos suficientes. Organizado y puntual fue uno de los pocos profesores que entregó el syllabus de la asignatura el primes día de clase.

Aunque jamás éstudie Educcinelli Conversom, siempre hemos admirado su innata técnica didáctica: Certera, equilibrada y muy participativa. Presentaba la clase y desarrollaba el tema utilizando ejemplos cuidadosamente seleccionados. En determinado momento hacía circular una hoja mimeografiada en la cual debíamos efectuar los habituales ejercicios de aplicación. Trabajábamos textos de Literatura Española y Peruana, fue Escobar (nunca lo olvido) quien me hizo conocer tempranamente las creaciones de Martín Adán y asombrarme de que un joven peruano de apenas 19 años pudiera realizar la hazaña de escribir La casa de cartón. En cierta oportunidad, por falta de hábito, a regañadientes, recibí el encargo de leer las 150 páginas de El abuelo del rey de Gabriel Miró. La obra fue para mí una verdadera revelación, me tropecé con un autor dueño de una bella prosa, por esta vía -siempre con la ayuda de Escobar-, poco a poco, me fui interesando en otros autores de la Generación del 98 como Unamuno, Valle-Inclán, Pío Baroja y el que más tarde sería mi preferido, Azorín. En otro momento del desarrollo de la materia, nos medimos con los 
Cuentos malévolos de Clemente Palma, hirieron nuestra conciencia de lector primerizo tanto "Los canastos" como "Los ojos de Lima", carecíamos aún de las herramientas críticas que nos hubieran permitido identificar la narrativa modernista. No obstante, el progresivo afinamiento de mi sensibilidad se iba apuntando como un verdadero logro del curso de Castellano.

En aquel tiempo, analizar en la parte teórica de la materia a los maestros Ferdinand de Saussure, Charles Bally, Karl Vossler, Albert Sechehaye, Joseph Vendryes o el peruano Luis Jaime Cisneros (Lengua y estilo) se constituyó, por una parte, en un verdadero privilegio, pero de otro lado implicaba un redoblado esfuerzo de decodificación de textos.

Pensemos en lo que significa esta huella que el magisterio de Alberto Escobar había impreso durante un solo curso, en uno de tantos alumnos suyos. Cuando yo lo fui, Escobar llevaba apenas dos años enseñando, luego continuó por espacio de otros catorce: dieciséis en total, lo que supone haber sembrado el germen del saber humanístico en centenares de jóvenes. Y esto limitándonos a los que tuvimos la suerte de recibir directamente su enseñanza personal, a muchos otros les-llegó a travês de sus esmerados libros.

A poco de retornar Escobar de Cornell University (1961-1962) a donde fue para recibir entrenamiento en los principios teóricos y métodos de la entonces triunfante Lingüística Estructural Norteamericana; volví a tenerlo de

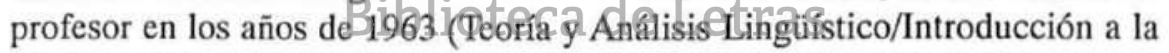
Filología Románica) y 1964 (InifterpretaciỏndelTextosoLiterarios). Después de este último año no tuve el privilegio de tenerlo como profesor, pero circunstancias personales permitieron que mi relación con él prosiguiera y se estrechase; así, para diseñar el syllabus de la asignatura de Lenguaje de la unidad de Estudios Generales trabajamos mancomunadamente durante el año 1970. De aquella experiencia guardo celosamente las Actas de las numerosas sesiones.

Saludo cordialmente a Alberto Escobar y a la vez quiero expresarle públicamente mi gratitud por las enseñanzas recibidas. 